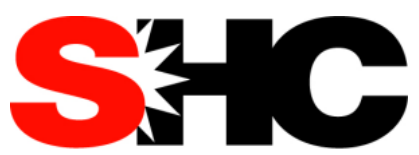

SOLAR HEATING \& COOLING PROGRAMME INTERNATIONAL ENERGY AGENCY
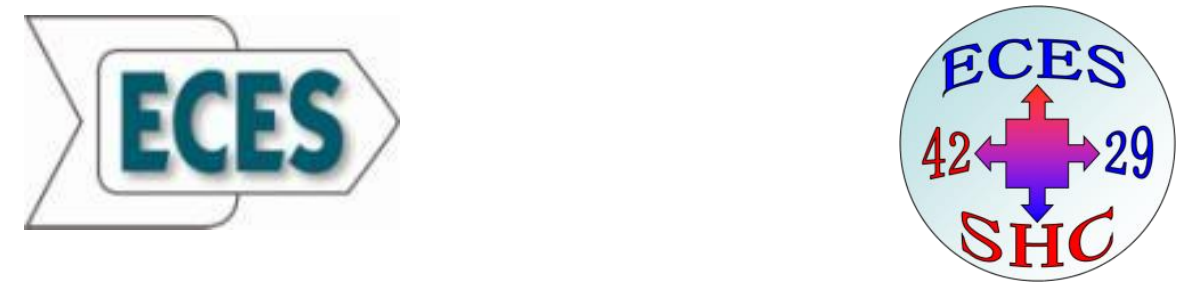

\title{
Standard to determine the heat storage capacity of PCM using hf-DSC with constant heating/cooling rate (dynamic mode)
}

\section{DSC 4229 PCM Standard}

\section{A technical report of subtask A2.1 of IEA-SHC 42 / ECES Annex 29}

Date: 31 January 2015

Stefan Gschwander ${ }^{1}$, Thomas Haussmann', Georg Hagelstein ${ }^{1}$, Aran Sole ${ }^{2}$, Gonzalo Diarce $^{3}$, Wolfgang Hohenauer, Daniel ${ }^{4}$ Lager, Christoph Rathgeber, ${ }^{4}$, Peter Hennemann $^{5}$, Ana Lazaro ${ }^{6}$, Harald Mehling ${ }^{7}$

${ }^{1}$ Fraunhofer ISE

Heidenhofstr. 2, 79110 Freiburg, Germany

Phone: 49-761-45885494

Fax: 49-761-45889000

e-mail: stefan.gschwander@ise.fraunhofer.de

${ }^{2}$ Universitat de Lleida

PI. de Víctor Siurana, 1, E-25003 Lleida, Spain

Phone: +34973702000

${ }^{3}$ University oft he Basque Country UPV/EHU, Spain

Rafael Moreno Pitxitxi 248013 Bilbao

Phone: +346014952

Fax: +346017800

${ }^{4}$ Austrian Institute of Technology

Donau-City-Straße 1, 1220 Vienna , Austria

\author{
${ }^{5}$ ZAE Bayern \\ Devision Bavarian Center for Applied Energy \\ Research \\ Walther-Meißner-Straße 6 \\ 85748 Garching, Germany \\ ${ }^{6}$ University of Zaragoza \\ C/ Pedro Cerbuna, 12, 50009 Zaragoza, Spain \\ Phone: +34 976761000 \\ Fax: +34 976761005 \\ ${ }^{7}$ ZAE Bayern \\ Division: Functional Materials for Energy \\ Technology \\ Am Galgenberg 87, \\ 97074 Würzburg, Germany
}




\section{IEA Solar Heating and Cooling Programme}

The Solar Heating and Cooling Program was founded in 1977 as one of the first multilateral technology initiatives ("Implementing Agreements") of the International Energy Agency. Its mission is

"to enhance collective knowledge and application of solar heating and cooling through international collaboration to reach the goal set in the vision of solar thermal energy meeting $50 \%$ of low temperature heating and cooling demand by 2050.

The member countries of the Program collaborate on projects (referred to as "Tasks") in the field of research, development, demonstration (RD\&D), and test methods for solar thermal energy and solar buildings.

A total of 53 such projects have been initiated to-date, 39 of which have been completed. Research topics include:

A Solar Space Heating and Water Heating (Tasks 14, 19, 26, 44)

A Solar Cooling (Tasks 25, 38, 48, 53)

A Solar Heat or Industrial or Agricultural Processes (Tasks 29, 33, 49)

A Solar District Heating (Tasks 7, 45)

A Solar Buildings/Architecture/Urban Planning (Tasks 8, 11, 12, 13, 20, 22, 23, 28, 37, 40, $41,47,51,52)$

A Solar Thermal \& PV (Tasks 16, 35)

A Daylighting/Lighting (Tasks 21, 31, 50)

A Materials/Components for Solar Heating and Cooling (Tasks 2, 3, 6, 10, 18, 27, 39)

A Standards, Certification, and Test Methods (Tasks 14, 24, 34, 43)

A Resource Assessment (Tasks 1, 4, 5, 9, 17, 36, 46)

A Storage of Solar Heat (Tasks 7, 32, 42)

In addition to the project work, there are special activities:

$>$ SHC International Conference on Solar Heating and Cooling for Buildings and Industry

> Solar Heat Worldwide - annual statistics publication

> Memorandum of Understanding with solar thermal trade organizations

> Workshops and conferences 


\section{Country Members}

Australia
Austria
Belgium
China
Canada
Denmark
European Commission

Germany
Finland
France
Italy
Mexico
Netherlands
Norway
Portugal

Singapore

South Africa

Spain

Sweden

Switzerland

Turkey

United Kingdom

United States

\section{Sponsor Members}

European Copper Institute ECREEE

Gulf Organization for Research and Development RCREEE

\section{Further information:}

For up to date information on the IEA SHC work, including many free publications, please visit www.iea-shc.org. 


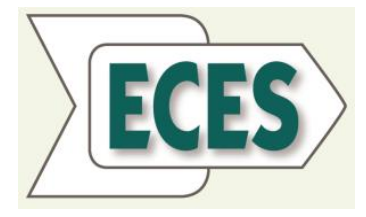

IEA Energy Conservation Through Energy Storage Programme

The International Energy Agency (IEA), based in Paris, is an autonomous agency linked with the Organisation for Economic Co-operation and Development (OECD). The IEA is the energy forum for 26 Member countries. IEA Member governments are committed to taking joint measures to meet oil supply emergencies. They have also agreed to share energy information, to co-ordinate their energy policies and to co-operate in the development of rational energy programmes.

The R\&D programme Efficient Energy End-Use Technologies contains 14 different Implementing Agreements (IAs) of which one is the IA on energy storage. The full name of this IA is Energy Conservation though Energy Storage (ECES IA). This IA was founded in 2004 and intends to promote co-operative research, development, demonstrations and exchanges of information regarding energy conservation through energy storage.

The continued development, application and deployment of energy efficient end-use technologies has the potential to significantly reduce energy consumption and greenhouse gases in the buildings, electricity generation, industry, and transport sectors. Energy storage technologies can overcome the temporal mismatch between energy supply and demand, especially regarding renewable energy technologies, the use of waste energy and energy from ambient sources such as cold from the natural environment.

Active participants in ECES IA are at present:

$\begin{array}{lll}\text { Belgium } & \text { Germany } & \text { Sweden } \\ \text { Canada } & \text { Italy } & \text { USA } \\ \text { China } & \text { Japan } & \text { Turkey } \\ \text { Finland } & \text { Korea } & \\ \text { France } & \text { Norway } & \end{array}$

Three sponsors are participating in the ECES at the moment:

IF Technology B.V. (Netherlands)

Institute of Heat Engineering, University of Technology of Warsaw (Poland)

Energesis Ingeniería, S.L. (Spain). 
Other countries have signed the agreement but are not presently engaged in the activities. Further countries have recently shown interest in participating in the near future, including countries from Eastern Europe.

The work within the ECES IA is lead by an Executive Committee (XC) and the work undertaken by this $\mathrm{XC}$ is done by mutual agreements defined in Annexes as listed on the next page. The work is led by Chairman Halime Paksoy (Turkey) and Secretary Hunay Evliya (Turkey).

To find ECES publications and learn more about the Programme visit http://www.ieaeces.org or contact the ECES Secretariat, Hunay Evliya, e-mail: hevliya@cu.edu.tr 
Ongoing Annexes:

Annex $20 \quad$ Sustainable Cooling with Thermal Energy Storage

Annex 21 Thermal Response Test for Underground Thermal Energy Storages

Annex 22 Thermal Energy Storage Applications in Closed Greenhouses

Annex 23 Applying Energy Storage in Ultra-low Energy Buildings

Annex $24 \quad$ Material Development for Improved Thermal Energy Storage Systems

Annex 25 Surplus Heat Management using Advanced TES for CO2 mitigation

Annex 26 Electric Energy Storage: Future Energy Storage Demand

Completed Annexes:

Annex $1 \quad$ Large Scale Thermal Storage Systems Evaluation

Annex 2 Lake Storage Demonstration Plant in Mannheim

Annex $3 \quad$ Aquifer Storage Demonstration Plant in Lausanne Dorigny

Annex $4 \quad$ Short Term Water Heat Storage Systems

Annex 5 Full Scale Latent Heat Storage Installations

Annex $6 \quad$ Environmental and Chemical aspects of Thermal Energy Storage in Aquifers and Research and Development of Water Treatment Methods

Annex $7 \quad$ Innovative and Cost Effective Seasonal Cold Storage Applications

Annex $8 \quad$ Implementing Underground Thermal Energy Storage Systems

Annex 9 Electrical Energy Storage Technologies for Utility Network Optimization

Annex 10

Phase Change Materials and Chemical Reactions for Thermal Energy Storage

Annex 12

High-Temperature Underground Thermal Energy Storage (HT UTES)

Annex 13

Design, Construction and Maintenance of UTES Wells and Boreholes

Annex 14

Cooling with TES in all Climates

Annex 17 Advanced Thermal Energy Storage Techniques - Feasibility Studies and Demonstration Projects

Annex 18 Transportation of Thermal Energy Utilizing Thermal Energy Storage

Annex 19 Optimised Industrial Process Heat and Power Generation with Thermal Energy Storage 


\section{Contents}

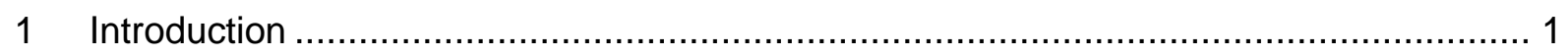

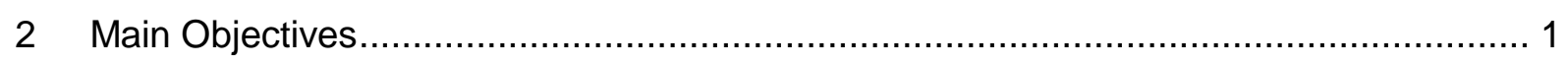

2.1 Scope of the IEA task 42 / Annex 29 Standard ............................................... 1

2.2 General remarks .................................................................................. 1

2.3 Number of samples and measurements................................................... 1

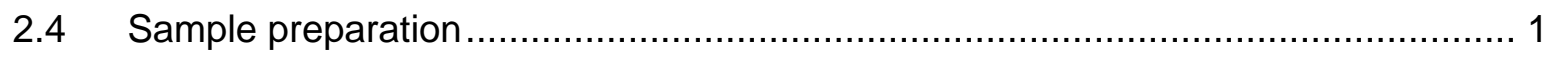

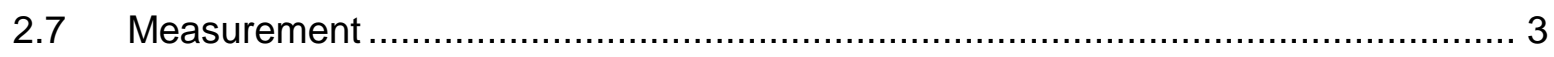

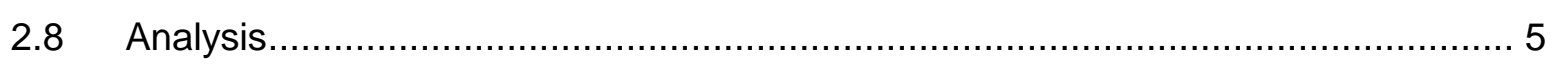

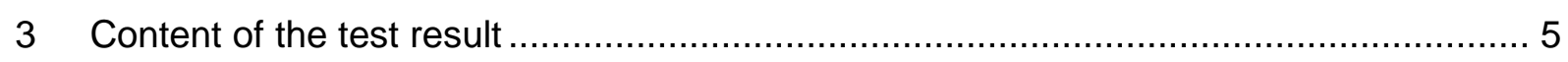

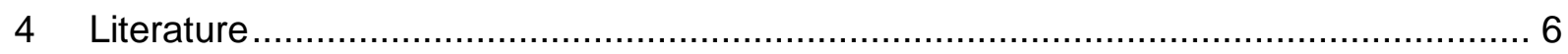




\section{Introduction}

The measurement procedure defined in this document is based on the already existing standard RAL-GZ 896 page (www.PCM-RAL.de). The T4229 is extending the procedure for PCM-characterization using DSCs by:

- Definition for the calibration of the DSC

- Definitions/suggestion for the sample preparation

- Detailed description for the measurement

- $\quad$ Suggestion for the improvement of the measurement results (analyzes/evaluation)

\section{Main Objectives}

\subsection{Scope of the IEA task 42 / Annex 29 Standard}

This standard is valid for the determination of the heat storage capacity of PCM using hfDSC with constant heating / cooling rate (dynamic mode) (Modulated or stepwise is not considered)It gives additional guidelines and comments, specifically for using hf-DSC with constant heating / cooling rate (dynamic mode) on topics not treated or not treated in detail by the RAL-GZ 896 standard.

\subsection{General remarks}

- The sample for measurement must be representative

- Ensure there is no reaction between sample and crucible

- This procedure is not valid for samples showing degradation during the measurements

\subsection{Number of samples and measurements}

At least 3 samples per product must be investigated. At least one measurement must be carried out per sample (consisting of 4 cycles each (heating and cooling ramp) over the temperature range of the complete phase transition).

\subsection{Sample preparation}

Use typical sample mass:

- e.g. $10 \mathrm{mg}$ in hf-DSC(perform all measurements, heating rate test and sample measurements, with similar masses. Deviations of sample masses should be less than $\pm 20 \%$ )

- crucible must be filled less than $2 / 3 r d$ ( $1 / 3 r d$ gas volume for thermal expansion of the sample)

- sample should cover bottom surface

- resulting hf-signal must be within device resolution 
- good noise to signal ratio should be obtained

- The crucible should be closed (e.g. cold welded) if possible to avoid material losses or absorptions

Temperature range determination if phase transition temperature range is unknown do first scan with less than $10 \mathrm{~K} / \mathrm{min}$ heating and cooling rates including the whole assumed melting and crystallization range with respect to material temperature limitations

- determine required temperature range

- full melting and crystallization must be included (Always perform full cycles including heating and cooling measurements), but not beyond material limits (The temperature range must be selected, taking the manufacturer's data into account, such that the sample is not damaged; according RAL)

- heating rate must be constant during melting and crystallization (transient oscillation when going from isothermal to ramp or reverse must be considered)

\subsection{Heating rate determination - Process to ensure thermal balance / thermal equilibrium}

- perform a heating rate test (according RAL GZ 896)

- slow down the heating and cooling rate by halve from one full cycle to the next

- use typical heating rates for your device, e.g. hf-DSC: 4, 2, 1, 0.5, $0.25 \mathrm{~K} / \mathrm{min}$

- determine inflection points temperature of enthalpy plots, or peak temperature of heat flow signals

0 if the difference between inflection point or peak-temperature (from one heating and cooling ramp to the next slower one) is less than $0.2 \mathrm{~K}$ choose the slower one (Figure 2)

- if the cooling ramp cannot be analyzed (e.g. loop behavior of heat flow signal because of subcooling) then it is sufficient to just consider heating ramps

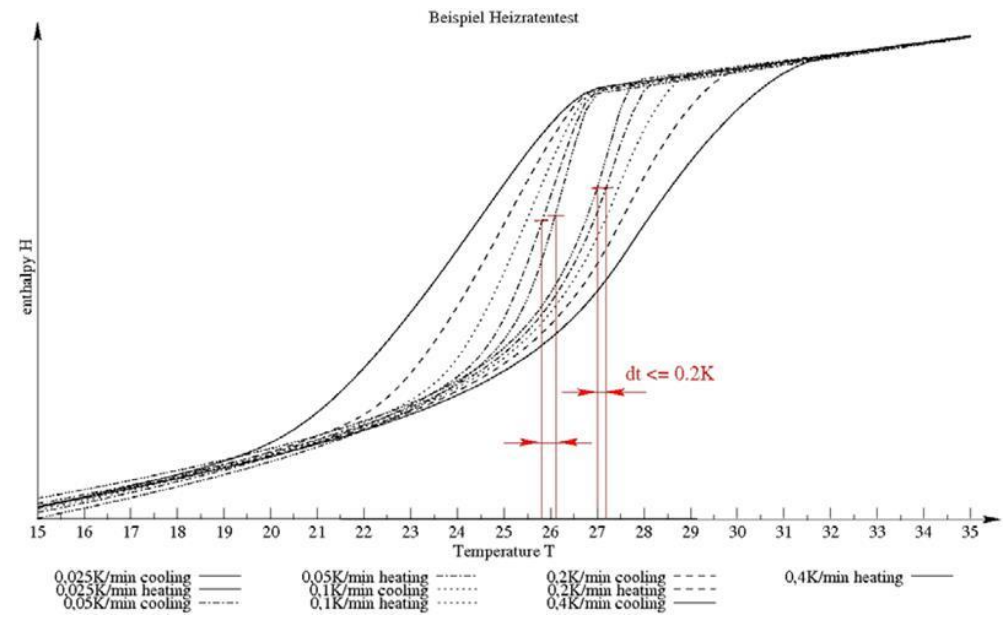

Figure 1: Heating rate test, constraint $0.2 \mathrm{~K}$ between inflection points 
o or if the temperature difference of the inflection points of heating and cooling is less than $0.5 \mathrm{~K}$ (Figure 2)

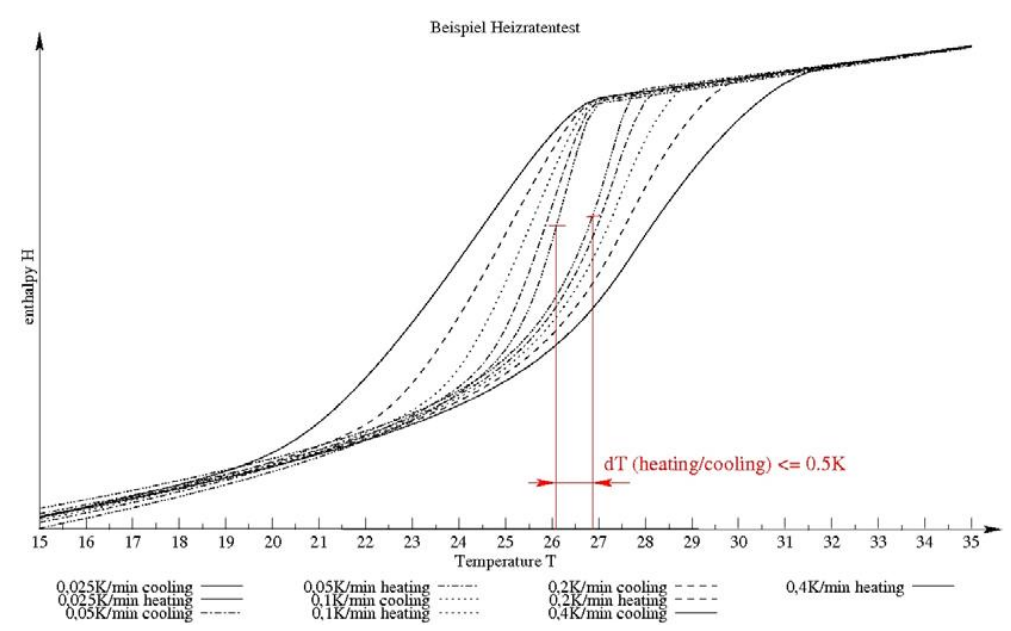

Figure 2: Heating rate test, constraint $0.5 \mathrm{~K}$ between infection points of heating and cooling

- determine temperature range for following measurement

○ use heating rate resulting from heating rate test

- select temperature range ensuring the whole phase transition is included

\subsection{Calibration}

- temperature calibration:

- perform calibration with determined heating rate

- select at least 3 calibration substances covering the desired temperature range

- e.g. Water, Gallium, Indium

- heat flow signal during calibration should be in the range of those measured with the sample

- set general temperature correction

- enthalpy calibration: (if not done using temperature calibration standards)

- perform calibration with determined temperature range

- select calibration substances covering the desired temperature range

- set general enthalpy correction

\subsection{Measurement}

1. Perform at least 3 different sample measurements of the same substance 
2. Use isothermal periods before and after each cooling/heating period to reach the thermal equilibrium and assure that DSC signal remains to be constant (Always ensure to reach thermal equilibrium in isothermal sections of the measurements for baseline construction according ASTM (Figure 4) and consider slow crystallization)

3. Measure all empty crucibles (with lid laid on it)

a. Use determined heating/cooling rates, use temperature limits and duration of isothermals chosen for the sample measurement, apply one cycle,

4. Apply sample and close crucible

5. Apply three measurement cycles

a. Use determined heating/cooling rates, apply cycle1 to 3 according to, use sample isothermals according to Figure 3

6. Apply one fast cycle (cycle 4) at the end of one of the measurements to check the enthalpy at higher heating rates (e.g. $4 \times$ determined heating rate, better signal to noise ratio)

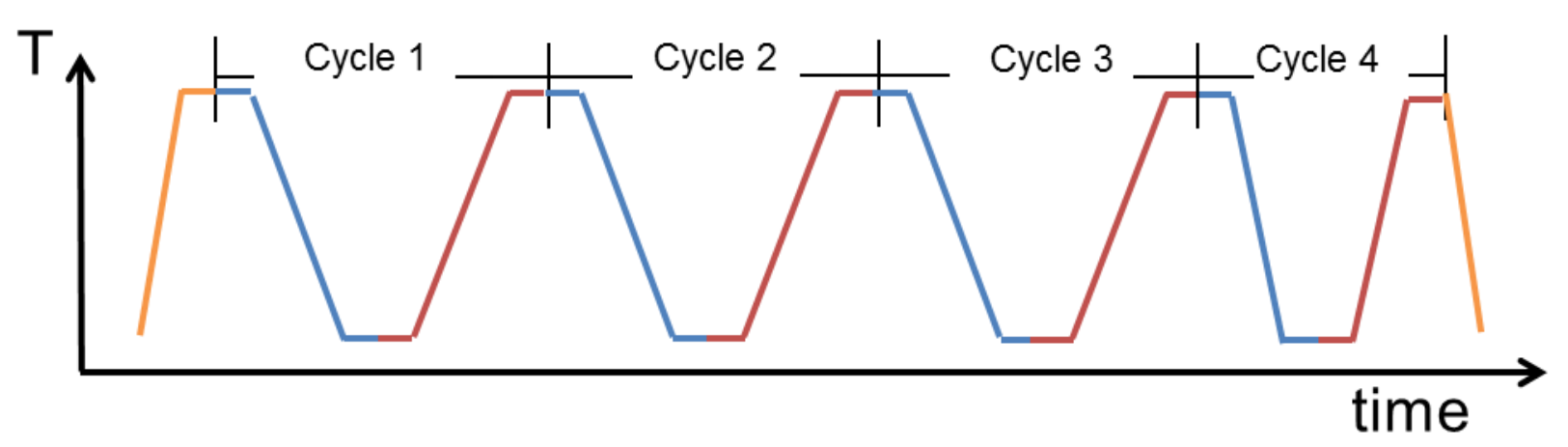

Figure 3: Heating-Cooling program 


\subsection{Analysis}

- Substract "zeroline" from blank and sample measurement for each cycle if the heat flow signal is not 0 at the end of the isotherms [1] (verify thermal equilibrium, see 2.7)

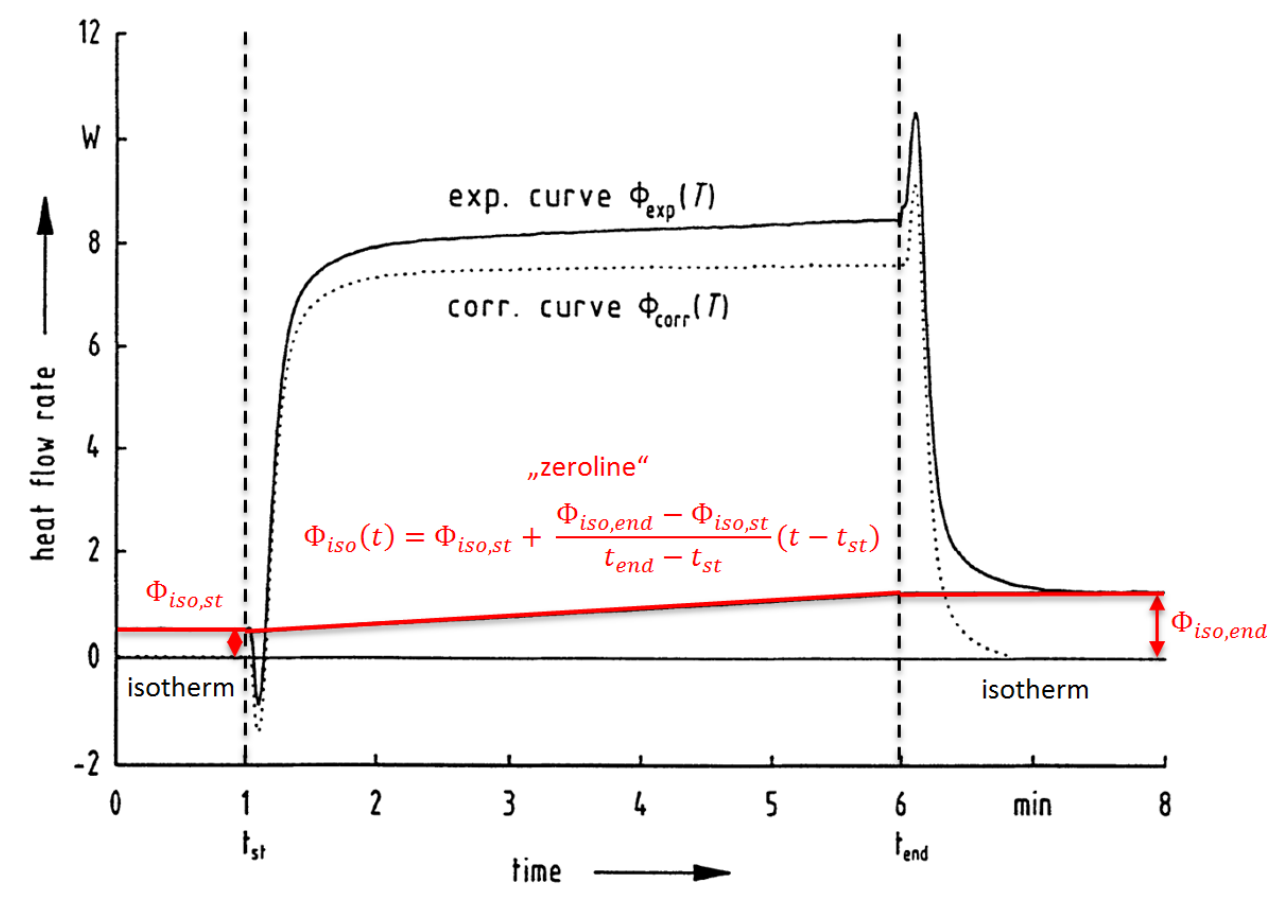

Figure 4: Base-Line construction according to ASTM

- Substract blank (empty crucible measurement) from sample measurement for each sample and each cycle

- Calculate the mean value and standard deviation of the 3 measurements (cycle 1 3) for onset, offset, peak temperature and heat of fusion as well as heat of crystallization

- Calculate the enthalpy curves

- Choose a temperature above $T_{\text {offset }}$ melting-peak (sample should be completely molten + e.g. $1-3 \mathrm{~K}$ ) as reference and set enthalpy at this temperature to $0 \mathrm{~J} / \mathrm{g}$

\section{Content of the test result}

- Export the data of the first 3 cycles of each sample measurement (for heating and cooling) in ASCIl-format. Data file must contain the columns in the order 1. Time [s], 2. Temperature $\left[{ }^{\circ} \mathrm{C}\right], 3$. heatflow $[\mathrm{mW} / \mathrm{mg}]$, 4. Enthalpy $[\mathrm{J} / \mathrm{g}]($ Table 1$)$ 
Table 1: Format od data file

\begin{tabular}{|l|r|r|r|}
\hline Time $[\mathrm{s}]$ & Temperature $\left[{ }^{\circ} \mathrm{C}\right]$ & Heatflow $[\mathrm{mw} / \mathrm{mg}]$ & Enthalpy $[\mathrm{J} / \mathrm{g}]$ \\
\hline 1184.00 & 5.498 & -0.0860 & -188.627 \\
\hline 1191.00 & 5.503 & -0.0861 & -188.604 \\
\hline$\ldots$ & & $\ldots$ & \\
\hline
\end{tabular}

- Upload the data for all 3 samples to www.thermalmaterials.ise.fraunhofer.de

\section{Literature}

Höhne, G.W.H., W. Hemminger, and H.J. Flammersheim, Differential Scanning Calorimetry. 1996: Springer Berlin Heidelberg. 